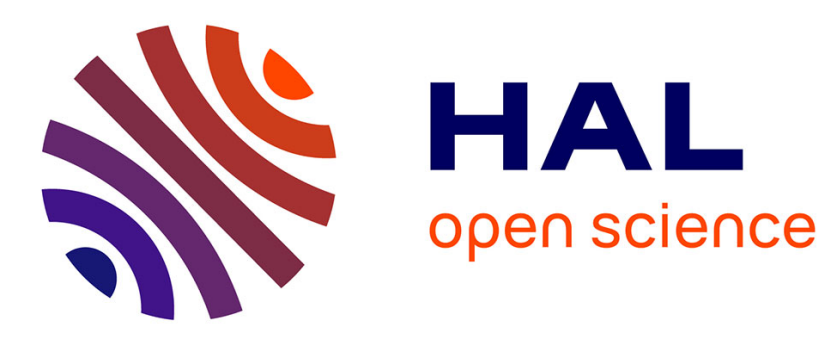

\title{
Health-seeking behaviour for childhood malaria: household dynamics in rural Senegal.
}

\author{
Aurélien Franckel, Richard Lalou
}

\section{To cite this version:}

Aurélien Franckel, Richard Lalou. Health-seeking behaviour for childhood malaria: household dynamics in rural Senegal.. Journal of Biosocial Science, 2009, 41 (1), pp.1-19. 10.1017/S0021932008002885 . ird-00418646

\section{HAL Id: ird-00418646 \\ https://hal.ird.fr/ird-00418646}

Submitted on 21 Sep 2009

HAL is a multi-disciplinary open access archive for the deposit and dissemination of scientific research documents, whether they are published or not. The documents may come from teaching and research institutions in France or abroad, or from public or private research centers.
L'archive ouverte pluridisciplinaire HAL, est destinée au dépôt et à la diffusion de documents scientifiques de niveau recherche, publiés ou non, émanant des établissements d'enseignement et de recherche français ou étrangers, des laboratoires publics ou privés. 


\title{
HEALTH-SEEKING BEHAVIOUR FOR CHILDHOOD MALARIA: HOUSEHOLD DYNAMICS IN RURAL SENEGAL
}

\author{
AURÉLIEN FRANCKEL* AND RICHARD LALOU† \\ *Institute of Demography, University of Paris X, Paris, France and $\dagger I R D$, \\ UMR 151-LPED, Marseilles, France
}

\begin{abstract}
Summary. Research on health care behaviour in sub-Saharan Africa usually considers the mother as the reference in the household when a child is sick. The study of health care management within the family is a key issue for understanding therapeutic rationales. This study was conducted in the region of Fatick in Senegal among 902 children with malaria-related fever. The data were taken from a retrospective quantitative survey conducted in all compounds of the DSS (Demographic Surveillance Site) of Niakhar. The results show that child care-taking is fundamentally a collective process: in $70 \cdot 9 \%$ of out-of-home resorts, the treatment decision was collective. The health care process of $68 \cdot 1 \%$ of morbid episodes involved several individuals. The involvement of the mother, the father and other relatives in the collective management of health care followed different logics. Each care-giver had a specific and complementary function depending on gender norms, intergenerational relations and characteristics of the family unit. Family management of illness aims at optimizing financial and human resources given the economic, logistical and social constraints on health care. Nevertheless, collective management also favoured home-based care, prevented good treatment compliance and delayed the resort to health facilities. These results suggest that health education campaigns should focus on an early involvement of fathers in health care-giving and also on the strengthening of the autonomy of mothers. Mothers' empowerment should give women more autonomy in their child's treatment choice. Lastly, there is a need to develop community health facilities and establish shared funding at the community level.
\end{abstract}

\section{Introduction}

During this last decade, social sciences have been strongly involved in malaria research, particularly under the impetus of the Multilateral Initiative on Malaria (MIM), Roll Back Malaria (RBM) and PAL+ programmes (in France). A number of 
studies have identified local illness categories and vernacular terminology for malaria. Research on health-seeking behaviour shows that health care is an on-going process, determined by choices and constraints defined by socioeconomic and cultural factors and the health system environment (McCombie, 1996; Williams \& Jones, 2004).

Decision-making and health care management within the household have been the focus of research. However, many of these studies only recognize the role of the patient or the care-giver, who are considered as individuals acting with economic and social autonomy (Fournier \& Haddad, 1995). Theoretical models of health behaviour, and in particular determinist and psychosocial approaches, are based on an individual-level perspective which contends that health rationality prevails in terms of health care costs and benefits (Kroeger, 1983; Godin, 1988). Furthermore, apart from a few anthropological and biosocial studies (Castle, 1993; Molyneux et al., 2002) that have shown the importance of social and economic interactions within the household, the study of health care among children generally focuses on the child's mother. Mothers are usually the reference in the family for children's illnesses, and the study of child care within the family is usually addressed in an indirect way through the mother. Family context effect is more often inferred than observed.

In sub-Saharan Africa, women are traditionally in charge of raising children, taking care of their health and well-being, and producing some material goods that are directly consumed by the family, such as food. According to this premise, the mother is naturally at the heart of home-based care management (Castle, 1993; Mwenesi et al., 1995). Yet in these societies, men hold the moral and economic power. Usually the father decides on and controls the child's treatment (Molyneux et al., 2002). However, decision-making seems distinct from care-giving during the health care process, as both functions involve differently the parents of the sick child.

The family in African societies is the place where disease symptoms are identified and decisions are made given that there is no institutional social protection system. The family is also the financial provider of health care. The involvement of the family in health care management is even stronger for children as they belong socially to the community. Children's health issues not only engage the restricted circle of biological parents but also the extended family circle. Health actions are the outcome of family and social interactions.

In the African context, the classical approach to health care, which usually focuses only on the mother, does not take into account some fundamental components of health care such as gender and family factors (Vlassoff \& Bonilla, 1994; Tanner \& Vlassoff, 1998; Molyneux et al., 2002). Yet, the analysis of these social dimensions is central to better understand the logics of health behaviour (McCombie, 1996; Heggenhougen et al., 2003). Given the recurrent gap, particularly for malaria treatment (William \& Jones, 2004), between medical recommendations and the population's actual health behaviours, the study of health care organization within the family context constitutes a major issue in the improvement of public health strategies (Molyneux et al., 2002).

This paper deals with health care behaviour for the management of childhood malaria in a rural setting in Senegal. The aim is to study the family as a health management group for childhood illness, and to identify the functions and constraints 


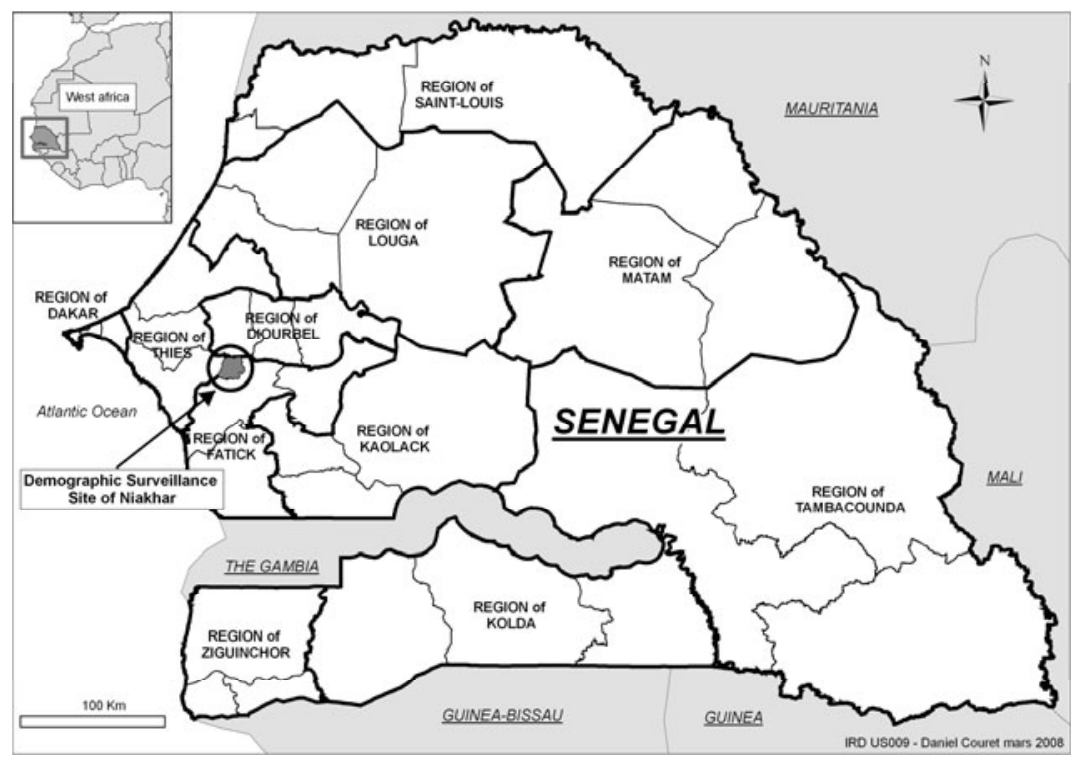

Fig. 1. Location of the study site.

of its organization. The first assumption is that health care organized within the family aims at improving the use of financial, human and cognitive resources while facing economic, health, cultural and social constraints. In addition, it is assumed that health care organization within the family is dependent on social and economic relations between family members, the division of tasks within the family and the perceptions of symptoms.

The article first describes the research setting and presents the survey and analysis methodologies. The findings concerning the distribution of roles within family members, particularly in terms of decision-making and care-giving, are then examined. Finally, the influence of family composition on conditions of child health care is addressed.

\section{Research context}

The study site is located in the region of Fatick, $150 \mathrm{~km}$ east of Dakar in Senegal (Figs 1 and 2). The population is predominantly Sereer (95\%). In 2001, the total fertility rate was high, close to 7 children per women, and the average age at first birth remained below 20 years of age. Post-marital residence is virilocal, polygamy is frequent and the average age difference between spouses is around 10 years. The age structure is very young: one-third of the population is below 10. The population is characterized by low education levels; two-thirds of adults were illiterate in 2004, and one out of every two children was not enrolled in school (Marra, 1998; Chippaux \& Arduin, 2005).

At the time of the survey in 2001, community infrastructure was poor in the study area. Electricity was not available in these communities and more than one-third of 


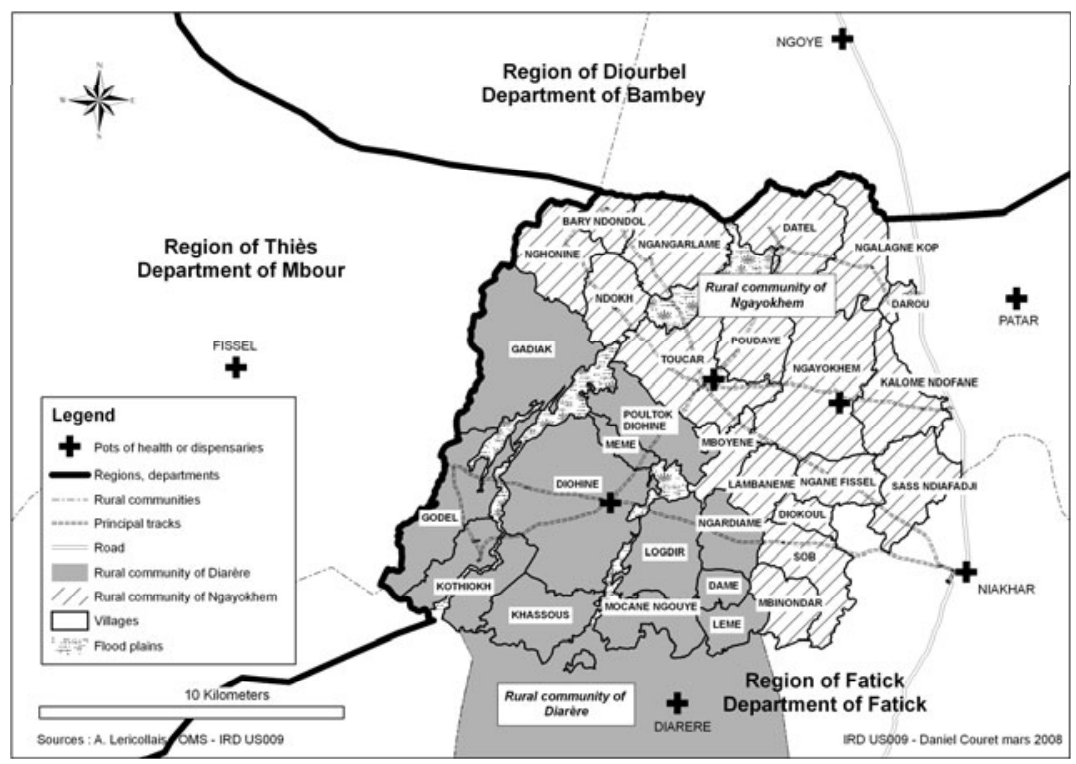

Fig. 2. Location of the surveyed villages.

the population drank salty water supplied by traditional wells. Villages are connected by dirt roads, almost impassable in the rainy season. Horse-drawn carts are the main means of transport. The population is basically engaged in agro-pastoral activities associated with staple (millet) and cash (groundnut) crops (Pelissier, 1953). In the last few decades, the area has faced increasing economic difficulties due to a traditional agricultural system crisis. This is the result of a combination of factors: rainfall shortage, yield losses due to land degradation, privatization of the groundnut industry, and a rise of population density from 85 inhabitants per square kilometre to more than 150 in less than 40 years. The population faces economic constraints; thus, they resort to seasonal migration, which provides rural households with extra incomes, and reduces the pressure on staple resources.

Malaria is the second most common cause of death among children, and accounts for nearly 30\% of child mortality (Etard et al., 2004). In the case of malaria, the health authorities recommended (at the time of the survey) a prompt resort to health facilities or the administration of $25 \mathrm{mg}$ of chloroquine per $\mathrm{kg}$ body weight given over three days, in spite of the rise of multidrug-resistant malaria in Senegal since the late 1980s (WHO, 2000; PNLP, 2001).

The modern health care infrastructure is poor in the study site: the population only has access to first-line health facilities that ensure primary health care, and do not have the laboratory equipment to diagnose malaria. There is a private Catholic dispensary located in Diohine and two public health centres situated in Toucar and in Ngayokhème, on which depend health huts, in Kalom-Ndofane and in Bary-Ndondol, run by community health agents (Fig. 2). Moreover, though the population has access to other health centres near the study area (i.e. in Niakhar, Diarère, Patar or Fissel), hospitals are far off and it takes hours to reach them. Health 
costs are established according to the Bamako Initiative: a financial mechanism where fees collected by patients are managed by the community to finance overall health care. The consultation fee at the health centre is 100 CFA francs (FCFA), a pack of ten chloroquine or paracetamol pills is sold for 100 FCFA, a bottle of chloroquine syrup costs 600 FCFA and a kit including three quinine injections costs 675 FCFA, each quinine phial costing 150 FCFA and the syringe 75 FCFA. A deficient supply of drugs is relatively frequent, particularly in paediatric form. The private dispensary has a fixed price of 500 FCFA, which includes consultation and treatment. Moreover, there are many traditional healers with specialized fields of practice. Infant and child mortality remained high at close to 150 per 1000 in 2001.

Although a large part of the population declares itself Catholic or Muslim, attachment to traditional animist beliefs remains very deep. The cosmogenic Sereer system considers the society of the living as a copy of that of ancestors whose souls ('pangols') live in trees or under the ground. Ancestors must be honoured on many occasions during social and economic life, but also during health treatment in order to keep the patient's vital energy, particularly in the case of children (Kalis, 1997; Gravrand, 1983; Heidenreich, 2000).

Malaria is identified in various local terms. The terminology used is more often descriptive and refers to seasons, symptoms or perceived causes. Malaria symptoms are addressed basically through two distinct aetiological categories with no direct interrelations. The local conception recognizes diseases related to febrile episodes with or without shivers, headaches, body aches and diarrhoea: these symptoms belong to the sumaan diig group, perceived as rather mild natural illnesses, whose seriousness stems from the duration of symptoms and apathy. Sumaan diig are fevers taking place during the rainy season: sumaan means fever, heat and ndiig means rainy season. This category includes a cun, o poog, jir ndiig and sibidu (Kalis, 1997; Faye, 2001). On the other hand, the population considers diseases associated with pernicious malaria (convulsive crisis, palpitations, coma) as the expression of supernatural illnesses that can lead to death. This is the case of diid (fear), kum a lass (evil doer), a cun (the pestle disease), o poox and o muss (the dog and cat disease); these illnesses are related to transgressions of taboos towards animals or objects in the compound (Franckel et al., 2007).

\section{Methods}

The analysis is based on data taken from a retrospective survey conducted in all the compounds of 29 villages of the area of Niakhar. This area is under demographic surveillance (Demographic Surveillance Site) by the Research Institute for Development (IRD), Paris. This survey was carried out in October and November 2001 during the rainy season, which is characterized by high malaria transmission (Robert et al., 1998). The survey design and questionnaires were drafted after a long stay amongst the population in the study area and after having conducted semi-directed interviews. The sample included feverish children. Interviewees were asked to declare if, at the time of the survey, each child was or had been affected by fever (sumaan), without referring to malaria or sibidu (malaria in Sereer). The reference period included 7 to 18 days before the time of the survey. This recall period aimed at 
limiting censored data regarding non-terminated illnesses and minimizing recall biases (Kroeger, 1983; McCombie, 1996).

To prevent clustering effects, only one sick child per household was selected, using a procedure which enables rank, age and sex effect control. The number of households with at least one child affected with fever was 902. Thus, the survey was conducted on these children. If symptoms persisted, all medical expenses were covered by the project. Additional data (economic level of household, educational level, household size, number of children under 6 in the household, household structure, village characteristics) were available with the quarterly census of the Demographic Surveillance Site (DSS) of Niakhar. No data on health care were available in the DSS longitudinal follow-up.

Before administering the questionnaires, the history of daily symptoms and treatment were listed on a form filled out by the interviewer and the child's mother. These data were the benchmark during the interview. The child's mother and father, and up to two persons other than the parents involved in the child's health care, were interviewed systematically. When more than two persons other than the parents participated in the child's care, they were selected according to their degree of involvement according to a specific algorithm. The stages of the health care process covered by the survey are as follows: illness identification, health care decisionmaking, escort of the child to out-of-home resorts, payment for possible health care expenses, health treatments whether prescribed or not.

Each stage of the health care process is analysed by status and role of each family member (mother, father, grandmother and other relatives). Two types of health care are examined: home care - including all spontaneous treatments given within the family (herbal tea, decoction, massages, fresh wrap, non-prescribed medications, etc.) - and external care. Resorts to health facilities were distinguished from visits to traditional healers. Results include descriptive statistics such as frequency, mean and relative risk (RR). The chi-squared test and Student's $t$-test were used in the analysis.

The multivariate regression is based on a backward stepwise binary logistic regression. The dependent variable modelled in this study is the probability of visiting a health facility within 48 hours after the beginning of first symptoms; an early consultation is one of the main WHO recommendations for malaria control that was adopted by the Ministry of Health in Senegal (PNLP, 2001). The variables entered in the model were first selected on the basis of the study's assumptions and literature review; they were then included if associated with an early consultation below a $0 \cdot 20$ level of significance after adjusting for age and sex of the child and parents' education. The STATA program was used for this analysis (STATA $^{\circledR}$ 8.0, 2003; Stata Corporation, College station, Texas, USA).

The model also included variables describing family structure and health care management: compound size, number of households in the compound, number of children under age 6 in the household, child-adult ratio, permanent presence of the father in the family, presence of a paternal uncle or grandmother in the compound, and the person(s) usually entitled to health care decision-making.

Included in the regression control variables related to several sets of explanations were: child's symptoms before visiting the health centre (illness with severe symptoms - at least high-grade fever, discomfort and/or vomiting on Day 1 and Day 2 - is 
compared with illness with symptoms of weak intensity); perception of the illness episode; parents' attitude towards biomedical treatment for malaria; perceived origin, causes and symptoms of malaria; the illness context; age, sex and rank of the child; medical history of the child; parents' age; religious beliefs; household's economic status (assessed from a factor analysis on ownership of goods and equipment such as animals and farming equipment, livestock-fattening, type of lighting, water access, sanitation, number of millet granaries, cut in the number of meals per day due to lack of money); parents' level of education; marital status; parents' migration experience; outward-looking sociability (regular use of the telephone and market attendance); family ethnic group and caste; distance to the nearest health facility; distance to the main dirt roads; characteristics of the village in terms of presence of a health facility, population density and proportion of residents having attended school; use of non-prescribed medication before the external resort; visit to the traditional healer before visiting the health centre.

\section{Results}

All the children in the sample had a fever that could be combined with other symptoms such as headaches, body aches, drowsiness and lack of appetite. The main malaria-related signs are: vomiting, diarrhoea, asthenia, skin swelling (which refers to the Sereer classification to the disease of Diid), icterus and convulsions. Most of the 902 illness episodes were cured in a short period after an average of 4.6 days $(\sigma=1.8$ days, $n=703$ ); but five of the surveyed children died. Overall these results match with malaria epidemiology in this area: the great majority of malaria episodes are mild; however, $2 \%$ to $5 \%$ of malaria episodes caused by $P$. falciparum develop into an acute malaria episode: half of these cases are followed by death (Snow et al., 2000).

Nearly $75 \%$ of respondents considered the health facility as the most appropriate resort to treat simple fever without complications; only $15 \%$ of respondents used self-medication and $10 \%$ used traditional therapy, either at home or by going to a traditional healer. However, biomedical care was perceived as not working on symptoms related to acute malaria, for which the preferred care option was the traditional healer. The mechanism of malaria infection also remained widely unknown: the relationship with the rainy season was suspected by $63 \%$ of adults, but the exclusive role of mosquitoes in the transmission was only identified by $35 \%$. In this case, respondents neither grasped the notion of an infectious bite nor the relation of stagnant waters with proliferation of Anopheles mosquitoes.

Home-based treatment was the principal form of treatment for sick children: $91 \cdot 1 \%$ were given one or several in-home treatments. Home-based treatments were various, multiform and more often administered simultaneously. Self-medication was the principal home-based treatment; however antipyretic medications were used much more than anti-malaria drugs - respectively $64 \cdot 7 \%$ and $18 \cdot 2 \%$ of total medications self-administered at home. More than $55 \%$ of pills given to children in self-medication were in the home pharmacy before malaria occurred. These stocks were partially supplied by remaining medications intentionally not totally used during previous morbid episodes, but also by the purchase of medications anticipating high morbidity during the rainy season. In this last case, medications were purchased in the general 
store $(47 \cdot 8 \%)$, a health facility $(25 \cdot 3 \%)$, and in a market or from medical hawkers $(26 \cdot 9 \%)$. Consultation outside the home was scarce but people resorted predominantly to biomedical care. While $21.6 \%$ of sick children were taken to health facilities, only $16.4 \%$ visited traditional healers. The average delay before the first out-of-home resort was $2 \cdot 4$ days. Traditional healers attracted their patients earlier than did health centres $(2 \cdot 3$ against $2 \cdot 6$ days, $t<0 \cdot 05)$.

The cost of home-based care (if not free) was about 100 FCFA. Traditional healers' fees were also low, close to 180 FCFA. Visits to health centres (consultation and treatment) were clearly more expensive, costing 1340 FCFA on average at the health centre and 720 at the health hut. Families mobilize on average a similar range of amounts: 1800 FCFA for a visit to the health centre, 850 FCFA at the health hut and 300 FCFA for the traditional healer. The indirect costs are small given that, in a great majority of cases, people walk or use a horse-drawn cart owned by the family or neighbours. By contrast, during the annual harvest, when agricultural activities are numerous, the consequences of the time spent to go and wait for a consultation at the health centre is significant.

The compliance to a chloroquine-based treatment was seldom in line with health authority recommendations. Patients were complying with medical instructions in terms of duration and dosage for less than $20 \%$ of treatments taken as self-medication and for $55 \%$ of treatments prescribed in a health facility.

\section{Health management: collective organization and specific responsibilities}

In $94 \cdot 1 \%$ of cases, the mother was the one who identified the child's illness. However, most health care decision-making was collective; decision-making involved at least two individuals for $70.9 \%$ of out-of-home resorts and $45 \cdot 5 \%$ of home-based care. Not less than three persons were engaged in $14.5 \%$ of external care and $6 \cdot 2 \%$ of home treatments. However, decision-making varied strongly according to the type of care: it involved more often several persons for self-medication than for traditional self-treatment $(\mathrm{RR}=1 \cdot 2, \quad p<0 \cdot 05)$; similarly, decision-making was more collective regarding a visit to the health facility than for other external resorts $(R R=1 \cdot 2$, $p<0 \cdot 05)$. In this collective context, the mother, the father and other relatives took the initiative regarding $69 \%, 14 \cdot 4 \%$ and $16.6 \%$ of treatments, respectively.

The mother took the child to an external consultation in $68.4 \%$ of cases while the father and other relatives escorted the child in a little more than $15 \%$ of cases. Moreover, the mother administered $78.8 \%$ of home care and prescribed treatments after consultation, whereas the father and other relatives respectively gave $9 \cdot 8 \%$ and $11.4 \%$ of these treatments. The child's mother and father were both important financial providers for health care costs, while the contribution of other relatives was relatively rare $(17 \%$ of the external resorts).

The mother, the father and other relatives had specific care strategies in terms of type of treatment they took charge of, decision-making and delay before resort. Thus, the father participated 1.6 times more in decisions regarding outside-the-home resorts than for home care $(\mathrm{RR}=1 \cdot 6, p<0 \cdot 01)$. By contrast, the mother took $1 \cdot 4$ times more the initiative in home care $(\mathrm{RR}=1.4, p<0.01)$ than in external resort. Furthermore, when an external resort was the decision of one person, it was more often initiated 


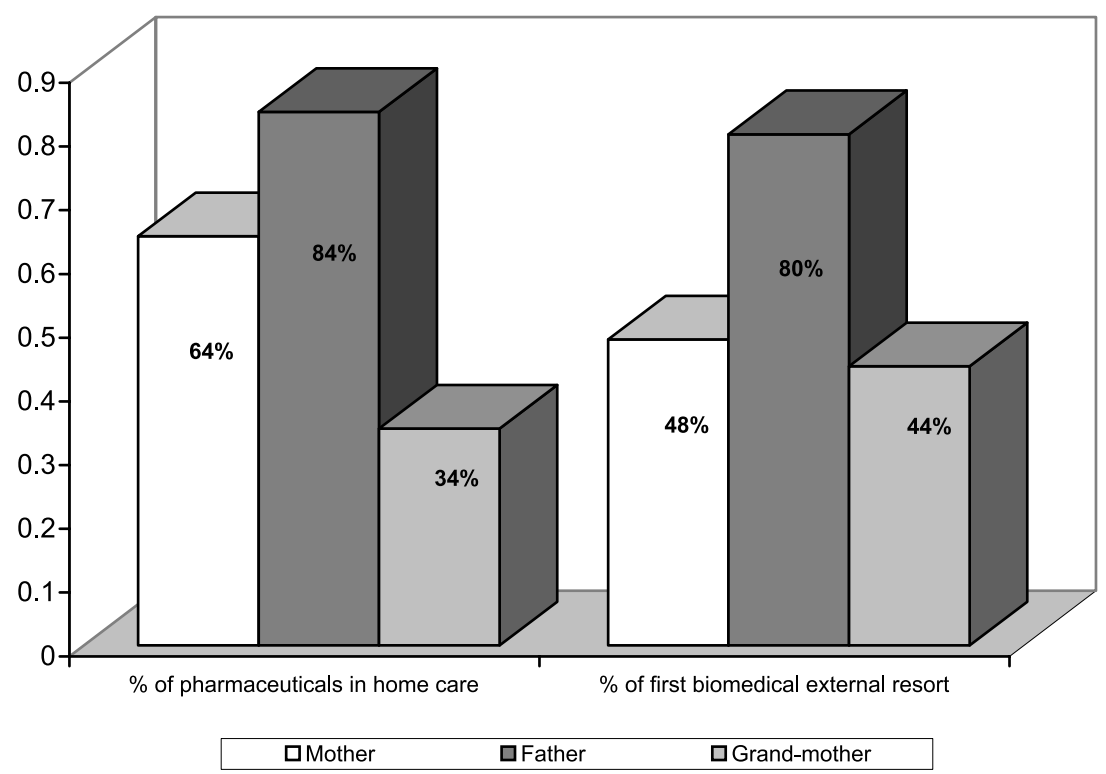

Fig. 3. Percentage of pharmaceuticals in first home care and first biomedical external resort according to the persons who suggested this type of treatment.

by the mother than by the father or other relatives - in respectively $40 \cdot 9 \%, 21 \cdot 8 \%$ and $12 \cdot 3 \%$ of cases $(p<0 \cdot 01)$.

Moreover, as shown in Fig. 3, the father used self-medication more than the child's mother $(\mathrm{RR}=1 \cdot 3, p<0 \cdot 01)$ or than the grandmothers $(\mathrm{RR}=2 \cdot 5, p<0 \cdot 01)$. Regarding external resorts, the father referred his child to the health centre more than did the mother $(\mathrm{RR}=1 \cdot 7, p<0 \cdot 01)$ or grandmothers $(\mathrm{RR}=1 \cdot 4, p<0 \cdot 01)$.

The distribution of roles concerning the care of a sick child varied according to the sex of the child, fathers being more involved with their sons, and mothers with their daughters. Thus, fathers more often suggested external resorts for boys $(\mathrm{RR}=1.9 ; p<0.05)$. Similarly, the child's age influenced the management of health problems within the family. The father's participation increased with the child's age: children brought by their father to consultation were significantly older than those brought by their mother $(4 \cdot 4$ years against 3.0 years; $t<0 \cdot 01)$; the father more often administered the prescribed treatments following a medical visit for children above 5 $(\mathrm{RR}=6 \cdot 1 ; p<0 \cdot 05)$.

The delay before an external resort varied significantly according to the individual who suggested the consultation. If the mother suggested external resort, the delay to visiting the health centre was shorter than if it was the father or another relative who did so (respectively $2 \cdot 4$ days, $2 \cdot 6$ days and 2.9 days, $t<0 \cdot 01$ ). The delay also varied according to the decision-making process: from $2 \cdot 2$ days if the decision was taken by one person to $2 \cdot 5$ days if several persons participated in the decision $(t<0 \cdot 1)$.

In a great majority of cases, only one person took charge of care expenses. Mothers more often provided for home-based care than for out-of-home resorts $(\mathrm{RR}=1.8 ; p<0 \cdot 01)$; they more often took charge of the expenses for a traditional 


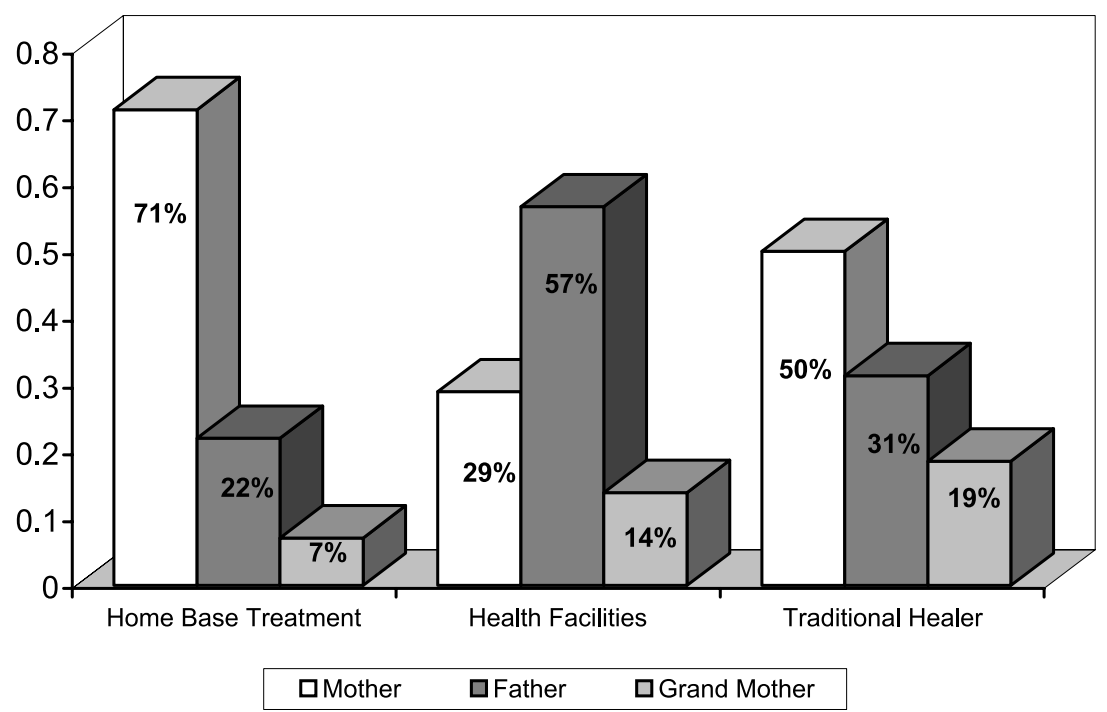

Fig. 4. Persons engaged in health care expenses by type of care.

healer than for a biomedical practitioner $(\mathrm{RR}=1 \cdot 3 ; p<0 \cdot 05)$. Conversely, fathers provided more for out-of-home resorts than for home care $(\mathrm{RR}=2 \cdot 0 ; p<0 \cdot 01)$ and more for visits to health facilities than to traditional healers $(\mathrm{RR}=2 \cdot 3 ; p<0 \cdot 01)$ (Fig. 4). The funds raised for out-of-home resorts varied according to the decisionmaking process and the identity of the individual who implemented the resort. On the one hand, funds gathered for the first out-of-home resort were higher in the case of a collective decision-making process than when the responsibility was up to one person (1072 FCFA against $844 \mathrm{FCFA} ;<0,05)$. On the other hand, the father raised an average of 2000 FCFA, which is 2.7 times more than what the mother could provide and $2 \cdot 0$ times more than what other relatives could support. It was observed that fathers escorted their child with amounts of money larger than necessary when they went to health facilities $(t<0 \cdot 01)$ and traditional healers $(t<0 \cdot 01)$.

Eventually, several persons were involved in the caring process of $68 \%$ of morbid episodes. This commitment concerned the different stages of health care such as health-related suggestions, discussions within the family, escorting, funding and administration of the treatment (Table 1). In 34\% of morbid episodes, care management involved only the two parents; relatives participated alone or with one or both parents in $35 \%$ of cases. At least three persons - the child's parents and one or several relatives - played a part in $14 \%$ of morbid episodes. The mother had the sole responsibility of the child's care in $30 \%$ of morbid episodes.

\section{Family organization and prompt biomedical resort}

To study family organization, the size of the compound, the number of adults and children under 6 living in the household, and the presence of the child's father, uncles and grandmothers were taken into account. In the study area, the traditional dwelling 
Table 1. Persons involved in morbid episodes leading to a treatment

\begin{tabular}{lcrr}
\hline & Involved persons & $\%$ & $N$ \\
\hline \multirow{2}{*}{ One single person } & Child's mother only & $29 \cdot 9$ & 261 \\
& Child's father only & $0 \cdot 8$ & 7 \\
& Other relative only & $1 \cdot 1$ & 10 \\
Several persons & Both parents & $34 \cdot 3$ & 299 \\
& Child's mother and other relative(s) & $18 \cdot 8$ & 164 \\
& Child's father and other relative(s) & $0 \cdot 9$ & 8 \\
Total & Both parents and other relative(s) & $14 \cdot 1$ & 123 \\
& & $100 \cdot 0$ & 872 \\
\hline
\end{tabular}

is a compound that consists of a group of rectangular dried mud-walled huts with thatched roofs enclosed by fences of millet stalks. Compounds have various sizes and shapes. The average size included 27 individuals ranging from 3 to 170 individuals per compound. The household, defined as the domestic and production unit, had an average size of 14 persons. In $10.5 \%$ of cases, children lived under the responsibility of a guardian. Among the surveyed children, 32.4\% lived in their paternal grandmother's compound, $31 \cdot 2 \%$ in their paternal uncle's one and $6 \cdot 2 \%$ in their maternal grandmother's one. Lastly, $22.4 \%$ of the surveyed children did not have their fathers living with them permanently (defined as a continuous presence in the 3 months prior to the morbid episode).

The size and composition of the family deeply affected the organization of health care. There was a significantly greater involvement of relatives $(\mathrm{R} R=1 \cdot 8 ; p<0 \cdot 1)$ when household size was above 25 persons, and when the number of children living in the household was $20 \%$ higher than the number of adults $(\mathrm{RR}=2 \cdot 4 ; p<0 \cdot 01)$. Furthermore, when the father did not reside permanently in the household due to his professional activities or polygamy, his participation dropped: he took the initiative less for the first out-of-home resort $(\mathrm{RR}=4 \cdot 2 ; p<0 \cdot 01)$, escorted his child less on a visit $(\mathrm{RR}=6 \cdot 7 ; p<0 \cdot 01)$ and took charge of the external resort less $(\mathrm{RR}=1 \cdot 6, \mathrm{p}<0 \cdot 05)$. The grandmother's presence in the compound limited the mother's power to suggest the first external resort $(\mathrm{RR}=1 \cdot 5 ; p<0 \cdot 01)$, while the presence of paternal uncles enhanced collective discussions within the family concerning the first out-of-home resort $(\mathrm{RR}=1 \cdot 2 ; p<0 \cdot 05)$.

Family composition also influences therapeutic practices. A backward stepwise logistic regression was used to assess the net effect of family composition variables on the likelihood of visiting a health facility in less than 48 hours. The model achieved a good adjustment of collected data with a likelihood ratio of around 24\% (Pseudo $R^{2}$ ) (Table 2).

Symptoms of the illness, representations of malaria and socio-demographic characteristics influenced the probability of promptly visiting a health facility. The child was brought quickly to the dispensary when he presented severe signs of malaria - high fever, vomiting, asthenia, poor appetite $(\mathrm{OR}=2.13 ; \mathrm{p}=0.002)$ - and when he resided in households where biomedical care was perceived as the only efficient 
Table 2. Logistic regression estimating the probability of visiting a health facility promptly $(N=852)$

\begin{tabular}{|c|c|c|c|c|c|}
\hline & $P>|z|$ & OR & $95 \% \mathrm{CI}$ & $n$ & $\%$ \\
\hline \multicolumn{6}{|l|}{ Characteristics of illness } \\
\hline Other characteristics of illness (Ref.) & \multirow[t]{2}{*}{$0 \cdot 002$} & \multirow[t]{2}{*}{$2 \cdot 13$} & \multirow[t]{2}{*}{$1 \cdot 33,3 \cdot 41$} & 573 & $63 \cdot 5$ \\
\hline Illness with severe symptoms on Day 1 and Day 2 & & & & 329 & $36 \cdot 5$ \\
\hline \multicolumn{6}{|l|}{ Perception of the treatment of sibidu $u^{\mathrm{a}}$} \\
\hline Traditional care is efficient (Ref.) & \multirow[t]{2}{*}{$0 \cdot 005$} & \multirow[t]{2}{*}{$2 \cdot 28$} & \multirow[t]{2}{*}{$1 \cdot 28,4 \cdot 07$} & 291 & $32 \cdot 3$ \\
\hline Only biomedical care is efficient & & & & 611 & $67 \cdot 7$ \\
\hline \multicolumn{6}{|l|}{ Age of child } \\
\hline $0-6$ years (Ref.) & \multirow[t]{2}{*}{$0 \cdot 036$} & \multirow[t]{2}{*}{$0 \cdot 52$} & \multirow[t]{2}{*}{$0 \cdot 28,0 \cdot 96$} & 649 & $72 \cdot 0$ \\
\hline $7-10$ years & & & & 253 & $28 \cdot 0$ \\
\hline \multicolumn{6}{|l|}{ Sex of child } \\
\hline Male (Ref.) & \multirow[t]{2}{*}{$0 \cdot 684$} & \multirow[t]{2}{*}{$0 \cdot 92$} & \multirow[t]{2}{*}{$0 \cdot 63,1 \cdot 36$} & 466 & $51 \cdot 7$ \\
\hline Female & & & & 436 & $48 \cdot 3$ \\
\hline \multicolumn{6}{|l|}{ Economic level of household } \\
\hline Non-rich household (Ref.) & \multirow[t]{2}{*}{$0 \cdot 124$} & \multirow[t]{2}{*}{$1 \cdot 52$} & \multirow[t]{2}{*}{$0 \cdot 89,2 \cdot 59$} & 338 & $37 \cdot 9$ \\
\hline Rich & & & & 555 & $62 \cdot 2$ \\
\hline \multicolumn{6}{|l|}{ Education level of parents } \\
\hline Illiterate or no complete primary schooling (Ref.) & \multirow[t]{2}{*}{$0 \cdot 761$} & \multirow[t]{2}{*}{$1 \cdot 09$} & $0 \cdot 62,1 \cdot 90$ & 712 & $78 \cdot 9$ \\
\hline One parent literate or with complete primary schooling & & & & 190 & $21 \cdot 1$ \\
\hline Ethnic group of the child & & & & & \\
\hline Sereer (Ref.) & $0 \cdot 025$ & $0 \cdot 28$ & $0 \cdot 09,0 \cdot 85$ & 876 & $97 \cdot 3$ \\
\hline Other ethnic group & & & & 24 & $2 \cdot 7$ \\
\hline Sociability practices & & & & & \\
\hline Other types of sociability (Ref.) & $0 \cdot 05$ & $2 \cdot 13$ & $1 \cdot 26,3 \cdot 59$ & 702 & $77 \cdot 8$ \\
\hline Outward-looking sociability & & & & 200 & $22 \cdot 2$ \\
\hline Size of compound & & & & & \\
\hline Average: 13-49 persons (Ref.) & $0 \cdot 018$ & $0 \cdot 47$ & $0 \cdot 25,0 \cdot 88$ & 558 & $24 \cdot 7$ \\
\hline Small: $3-2$ persons & $0 \cdot 083$ & $0 \cdot 53$ & $0 \cdot 26,1 \cdot 09$ & 222 & $62 \cdot 0$ \\
\hline Large: 50 perso & & & & 120 & $13 \cdot 3$ \\
\hline $\begin{array}{l}\text { Distance from compound to a health facility } \\
\text { (continuous variable) }\end{array}$ & $0 \cdot 013$ & $1 \cdot 00$ & $1 \cdot 00,1 \cdot 00$ & - & - \\
\hline Characteristics of village & & & & & \\
\hline Non-advantaged village (Ref.) ${ }^{\mathrm{b}}$ & $0 \cdot 031$ & 1.90 & $1 \cdot 06,3 \cdot 39$ & 601 & $66 \cdot 6$ \\
\hline Advantaged village & & & & 301 & $33 \cdot 4$ \\
\hline Use of medications as home treatment & & & & & \\
\hline Yes (Ref.) & $0 \cdot 000$ & $5 \cdot 80$ & $3 \cdot 45,9 \cdot 75$ & 537 & $59 \cdot 5$ \\
\hline No & & & & 365 & $40 \cdot 5$ \\
\hline Visit to a traditional healer before the health centre & & & & & \\
\hline Yes (Ref.) & $0 \cdot 003$ & $4 \cdot 14$ & $1 \cdot 63,10 \cdot 52$ & 120 & $13 \cdot 3$ \\
\hline No & & & & 782 & $86 \cdot 7$ \\
\hline Number of children below 6 years (continuous variable) & $0 \cdot 043$ & $0 \cdot 88$ & $0 \cdot 78,1 \cdot 00$ & - & - \\
\hline Presence of an uncle and paternal grandmother & & & & & \\
\hline No (Ref.) & $0 \cdot 010$ & $2 \cdot 08$ & $1 \cdot 19,3 \cdot 64$ & 726 & $81 \cdot 2$ \\
\hline Yes & & & & 168 & $18 \cdot 8$ \\
\hline Decision-making power & & & & & \\
\hline Decision-making power distributed otherwise (Ref.) & $0 \cdot 005$ & 1.98 & $1 \cdot 23,3 \cdot 19$ & 529 & $58 \cdot 7$ \\
\hline Father has all the power of decision & & & & 373 & $41 \cdot 3$ \\
\hline
\end{tabular}

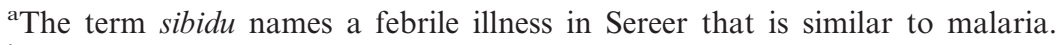

${ }^{\mathrm{b}}$ The classification of villages takes into account the level of equipment of the village, the dwelling density and children's education level. 
malaria treatment $(\mathrm{OR}=2 \cdot 28 ; p=0.005)$. Furthermore, the delay resorting to the health centre was longer as the child got older with a threshold starting from age 7 $(\mathrm{OR}=0.52 ; p=0.036)$; on the other hand, the Peul and Wolof, two ethnic groups not traditionally established in this area, resorted more promptly $(\mathrm{OR}=0 \cdot 28)$ to the dispensary then the Sereer. An outward attitude of parents, defined as those who use the telephone and attend weekly markets, also favoured a quick visit to a health centre $(\mathrm{OR}=2 \cdot 13)$. By contrast, the child's sex and the level of parental education are not predictors of a prompt visit to a health facility; likewise, the economic household level, measured by the goods and equipment owned by the household, did not seem to be associated with the household's capacity to rapidly raise funds for a visit at the health centre.

The distance to health facilities strongly influenced the probability of consulting a health centre. Therapeutic practices were also greatly associated with a prompt visit to the health centre: children who were given no self-medication $(\mathrm{OR}=5 \cdot 80 ; p<0 \cdot 001)$ and those who did not consult a traditional healer $(\mathrm{OR}=4 \cdot 14 ; p=0.003)$ increasingly resorted to a health facility and with a shorter delay.

Once all previously mentioned factors were considered, family composition had a strong influence on the probability of consulting quickly at the health centre. The resort to a health centre was favoured by the presence of the child's paternal uncle and grandmother in the household $(\mathrm{OR}=2 \cdot 08 ; p=0 \cdot 01)$. Conversely, visits to the health centre were less frequent in small $(\mathrm{OR}=0.47 ; p=0.018)$ or very large compounds $(\mathrm{OR}=0.53 ; p=0.083)$, and decreased regularly as the number of children below 6 living in the household grew. Moreover, the theoretical distribution of responsibilities for the child's care within the household clearly affected the probability of consulting at a health facility. In households where the father was referred as the only decision-maker, visits to health centres were more frequent $(\mathrm{OR}=1.98 ; p=0.005)$. At onset of illness, the father's control over decision-making and his prompt commitment in the therapeutic process can strengthen the ability to raise necessary funds for outside biomedical care. Conversely, when the decisionmaking process was shared by both parents with the father getting involved later in the process, the child was more frequently treated with home remedies or by traditional healers, given that the mother has little financial means or time at her disposal.

\section{Discussion}

The results show that health care-seeking concerning children, in rural Senegal, is an interactive process that involves most of the time at least two persons. Most of the illnesses are indeed managed by several persons: by the two parents in $34 \%$ of the cases, and by at least one of the parents and someone else in 35\% of the cases. However, less than $15 \%$ of illnesses lead to the involvement of three or more different persons. Thus, the illness management model is not a process that systematically engages all the members of the family, but appears to be a strategy to maximize human and financial resources in the face of the economic, logistic and social constraints of treatment seeking (Ryan, 1998; Molyneux et al., 2002; Williams \& Jones, 2004). Indeed, health care-seeking behaviour has to be replaced in the context 
of the study area where the population faces numerous constraints: the geographical distance of the health facility and its higher cost compared with other treatments; the rainy season as a period of increased morbidity with high peaks of malaria; the population's limited financial means due to the farming schedule with just one annual harvest; and restricted available time due to a heavy farm workload (Robert et al., 1998).

In this context, management of health care is likely to be collective according to various constraints related to out-of-home treatments. Biomedical health care needs time and money and stems from a family consultation ( $70 \%$ of the cases), whereas $45 \%$ of home-based treatments fall within individual decision-making due to its low cost and easy access. Moreover, the likelihood of visiting a health facility in less than 48 hours is related to the family's morphology and organization. The number of children, the number of present adults, the compound size and the decision-making process strongly influence the likelihood to consult. Health care in a collective setting seems to alleviate the impact of these constraints, at different levels, by: (i) making the most of family network resources; (ii) widening the range of therapeutic possibilities; (iii) maximizing care opportunities; and (iv) sharing expenses. Moreover, within a collective management, parents are not alone when facing a frequent but still ill-known illness. The study of health beliefs and knowledge in this area shows that there is an overlapping of numerous health beliefs with a rough knowledge concerning malaria causes, symptoms and treatment (Franckel et al., 2007). More generally, this situation strengthened the solidarity and asserted the identity of the group facing illness (Pescolido, 1992). As Sereer society is both matrilineal and patrilineal, solidarities can engage the uterine kin and patrilineal relatives during a morbid episode.

In this perspective, health behaviours express individual choices that are partially determined by gender, age and economic status (Pescolido, 1992; Mwenesi et al., 1995; Tanner \& Vlassoff, 1998; Oberlander \& Elverdan, 2000; Heggenhougen et al., 2003). The mother's, father's and other family member's commitments are largely adapted to the social, cultural and economic norms of the Sereer family. As a woman's status is established by her ability to have a healthy child, mothers must above all prove that they are capable of curing their child without outside help. Moreover, in this society steeped in a tradition where gender and intergeneration relations are very hierarchical, where virilocal residence is the rule and where spouse age differences are often close to 10 years, women are very dependent socially and economically; women's own budget represents less than $20 \%$ of that of men (Delaunay, 1998; Guigou et al., 1999; Guigou, 1999). Furthermore, women are in charge of heavy workloads (Garin et al., 1999). Besides taking care of their sick child, women must look after their other children, fetch water, cook and perform household chores and farm work. In this situation, they identify $95 \%$ of illnesses and administer nearly $80 \%$ of treatments, but are often unable to face the constraints of an expensive and distant biomedical resort. Consequently, although their perceptions and knowledge do not differ from those of men, they choose to consult, on most occasions, traditional healers, which are more accessible and affordable. Conversely, as the main holder of economic power within the family, the father provides for more expensive treatments if home care fails or the illness worsens (Troy, 1999). Although the father 
administers less than $10 \%$ of treatments and escorts only $15 \%$ of sick children to the health facility, he takes charge of $60 \%$ of the expenses and mobilizes on average 2.7 times more money than the mother for a biomedical consultation. Additionally, relatives' engagement represents an assistance to overcome health care constraints. Grandmothers or other family members do not substitute themselves initially for biological parents: they intervene secondly, and are less concerned by home care than by out-of-home resorts that they suggest, and fund and administer in respectively $8 \%$ and $15 \%$ of cases. Grandmothers are rather in favour of traditional healers but can also suggest biomedical care. When they are involved in the caring process, they use pharmaceuticals in 30\% of home-based care, and recommend health facilities in $45 \%$ of their out-of-the-home resorts. Table 3 shows how mothers, fathers and relatives are engaged in children's treatment-seeking.

Nevertheless, this general health management model varies according to several factors. As shown previously, health care-seeking constraints depend on family size and composition. The different care options have in fine a relative cost that is a function of time, energy, opportunities of travelling and financial help available for child care within the household. Likewise, family composition has an impact on the distribution of responsibilities. The autonomy of the child's mother is reduced when one of the child's grandmothers resides in the compound. Conversely, the mother's autonomy is widened, particularly regarding health care financial support, when the father is not living permanently in the compound. The involvement of the father also varies according to children's characteristics. A stronger commitment of the father can be observed for weaned children and for boys. Along this line, attention has been given to the intensity of the mother-child relationship in West Africa during the child's first years (Adjamagbo et al., 1999).

These findings express the key role of African family organization in the understanding of social and health phenomena. They are consistent with the results of many studies conducted in Africa on children's education, immunization coverage, nutritional status, fertility, use of health facilities and infant and child mortality risk (Bruce \& Lloyd, 1992; Castle, 1993; Kirumira, 1995; Lloyd \& Blanc, 1996; Gage et al., 1996, 1997). However, further research on the social and family context of health care-taking is necessary. Other tools of data analysis should be used in order to overcome the limits of a methodology too exclusively quantitative. Quantitative evidence is not sufficient to investigate household rationales relative to health care seeking. Qualitative data should allow an in-depth examination of people's behaviour about the issues under consideration. In addition, other rural or urban contexts should be explored to expand the scope of these findings.

\section{Conclusion}

In the study context - an environment characterized by a low level of knowledge of malaria, limited economic resources and poor health care infrastructure - these findings show that child illness management involved the mother, the father and other relatives in a process where each of them assumes specific and complementary functions. The adopted treatment-seeking patterns suggest a much more complex and subtle schema than the stereotyped one where the mother has the sole responsibility 
Table 3. Main characteristics of parents/relatives' involvement in the therapeutic process

\begin{tabular}{|c|c|c|c|c|}
\hline & Decision-making & Type of care & Administration & Funding \\
\hline Mother & $\begin{array}{l}\text { Home-based care: alone } \\
\text { External care: alone or collectively }\end{array}$ & Traditional and biomedical & Very frequent & Frequent \\
\hline Father & Collectively & Biomedical & Infrequent & $\begin{array}{l}\text { Home-based care: infrequent } \\
\text { External care: frequent biomedical }\end{array}$ \\
\hline Grandmother(s) & Collectively & Traditional & Infrequent & Infrequent \\
\hline Other relative(s) & Collectively & Biomedical & Infrequent & Infrequent \\
\hline
\end{tabular}


of her child's well-being. This pragmatic organization, based on norms prevailing in Sereer society, increases therapeutic options, comforts parents and enables families to cope with health care constraints, particularly for those with a low financial capacity and limited human resources.

Nevertheless, this pattern of illness management also has many consequences in terms of public health regarding the level of use of treatment protocols recommended by health authorities, the delay of response and compliance with treatments. The social and cultural context in this area favours a long home treatment given that the mother is the main care-giver and holds a limited capacity for action. Furthermore, collective care-taking delays resort to health facilities and lowers good treatment compliance. In this perspective, the findings suggest that health education campaigns should take more into account the individuals in the family unit who distribute information, take the initiative and support various treatments. Moreover, the high cost of biomedical resort appears strongly discriminating for mothers, who have the lowest capacity to mobilize money. The development of health facilities and shared funding at the community level should foster mothers' empowerment regarding children's health care.

\section{Acknowledgments}

The authors wish to thank Florence Waïtzenegger for the paper's translation from French into English, as well as the anonymous referees of the Journal of Biosocial Science for their useful comments.

\section{References}

Adjamagbo, A., Guillaume, A. \& Koffi, N. (eds) (1999) Santé de la Mère et de l'Enfant : Exemples Africains. IRD, Paris, p. 165.

Bruce, J. \& Lloyd, C. (1992) Finding the Ties That Bind: Beyond Headship and Household. Population Council Working Paper No. 41.

Castle, S. (1993) Intra-household differentials in women's status: household function and focus as determinants of children's illness management and care in rural Mali. Health Transition Review 3(2).

Chippaux, J-P. \& Arduin, P. (2005) Recherche Intégrée sur la Santé des Populations à Niakhar (Sahel Sénégalais). IRD, Paris, p. 32.

Delaunay, V. (1998) Nuptialité des célibataires. In Delaunay, V. (ed.) La Situation Démographique et Épidémiologique dans la Zone de Niakhar au Sénégal - 1984-1996. Orstom, Dakar, pp. 39-45.

Etard, J. F., Le Hesran, J.Y., Diallo, A., Diallo, J. P., Ndiaye, J. L. \& Delaunay, V. (2004) Childhood mortality and probable causes of death using verbal autopsy in Niakhar, Senegal, 1989-2000. International Journal of Epidemiology 33(6), 1286-1292.

Faye, S. L. B. (2001) Modes de représentations du paludisme chez l'enfant et recours aux soins en milieu sereer: Niakhar, Fatick. Mémoire de DEA, UCAD, IRD, Dakar, p. 82.

Fournier, P. \& Haddad, S. (1995) Les facteurs associés à l'utilisation des services de santé dans les pays en développement. In Gérard, H. \& Piché, V. (eds) Sociologie des Populations. PUM/AUPELF-UREF, Montreal, pp. 289-325. 
Franckel, A., Lalou, R., Delaunay, V., Adjamagbo, A., Faye, S., Waïtzenegger, F. \& Le Hesran, J-Y. (2007) Paludisme chez l'enfant et recours aux soins en milieu rural sénégalais: approches croisées. In Adjamagbo, A., Msellati, P. \& Vimard, P. (eds) Changements de Comportement et Santé de la Reproduction dans les pays du Sud. Académia-Bruylant, Louvain-la-Neuve.

Gage, A. J., Sommerfelt, A. E. \& Piani, A. L. (1996) Household Structure, Socioeconomic Level and Child Health in Sub-Saharan Africa. Demographic and Health Surveys Analytical Reports No. 1. Macro International, Inc., Calverton, MD.

Gage, A. J., Sommerfelt, A. E. \& Piani, A. L. (1997) Household structure and childhood immunization in Niger and Nigeria. Demography 34(2), 295-309.

Garin, P., Guigou, B. \& Lericollais, A. (1999) Les pratiques paysannes dans le Sine. In Lericollais, A. (ed.) Paysans Sereer. Dynamiques Agraires et Mobilités au Sénégal. IRD, Paris, pp. 209-298.

Godin, G. (1988) Fondements psychosociaux dans l'étude des comportements reliés à la santé. Santé et Société 2, 5-20.

Gravrand, H. (1983) Cosaan. La Civilisation sereer. Les Origines. Nouvelles Editions Africaines, Dakar/Paris.

Guigou, B. (1999) Les fondements de l'économie locale. Les usages de l'argent et de la richesse: solidarités, réciprocité et hiérarchie des statuts dans le Sine. In Lericollais, A. (ed.) Paysans Sereer. Dynamiques agraires et mobilités au Sénégal. IRD, Paris, pp. 485-520.

Guigou, B. \& Lericollais, A. (1999) Crise de l'agriculture et marginalisation économique des femmes sereer siin (Sénégal). In Lericollais, A. (ed.) Paysans Sereer. Dynamiques Agraires et Mobilités au Sénégal. IRD, Paris, pp. 45-64.

Heggenhougen, H. K., Hacketal, V. \& Vivek, P. (2003) The Behavioural and Social Aspects of Malaria and its Controls: An Introduction and Annotated Bibliography. UNCP/World Bank/WHO special programme for research and training in Tropical diseases (TDR), Geneva, Vol. 03.

Heidenreich, F. (2000) Recherches ethnomédicales en pays Sereer (Sénégal). L'autre, Vol. I, No. 3, pp. 547-552.

Kalis, S. (1997) Médecine Traditionnelle, Religion et Divination chez les Sereer. L'harmattan, Paris.

Kirumira, E. A. (1995) Familial relationships and population dynamics in Uganda: a case study of fertility behaviour in the central region. PhD dissertation, Social Sciences Department, University of Copenhagen, Denmark.

Kroeger, A. (1983). Anthropological and socio-medical health care research in developing countries. Social Science and Medicine 17(3), pp. 147-161.

Lloyd, C. B. \& Blanc, A. K. (1996) Children's schooling in sub-Saharan Africa: the role of fathers, mothers and others. Population and Development Review 22(2), 265-291.

McCombie, S. C. (1996) Treatment-seeking for malaria: a review of recent research. Social Science and Medicine 43, 933-945.

Marra, A. (1998) Caractéristiques de la Population In Delaunay, V. (ed.) La Situation Démographique et Épidémiologique dans la Zone de Niakhar au Sénégal - 1984-1996. Orstom, Dakar, pp. 23-31.

Molyneux, S. C., Murira G., Masha, J. \& Snow, R. W. (2002) Intra-household relations and treatment decision-making for childhood illness: A Kenyan case study. Journal of Biosocial Science 34, 109-131.

Mwenesi, H., Harpham, T. \& Snow, R. W. (1995) Child malaria treatment practices among mothers in Kenya. Social Science and Medicine 40(9), 1271-1277.

Oberlander, L. \& Elverdan, B. (2000) Malaria in the United Republic of Tanzania: Cultural considerations and health-seeking behaviour. Bulletin of World Health Organization 78(11), 1352-1357. 
Pelissier, P. (1953) Les Paysans Sérères. Essai sur la Formation d'un Terroir du Sénégal. IHED, Saint-Louis (SN), p. 27.

Pescolido, B. A. (1992) Beyond rational choice: the social dynamics of how people seek help. American Journal of Sociology 97(4), 1096-1138.

PNLP (2001) Les Objectifs de la Lutte Contre le Paludisme au Sénégal. 2001 report. Ministère de la Santé, direction de la Santé, division des Maladies Transmissibles, Programme National de Lutte Contre le Paludisme.

Robert, V., Dieng, H., Locouarn, L., Traoré, S. F., Trape, J-F., Simondon, F. \& Fontenille, D. (1998) La transmission du paludisme dans la zone de Niakhar, Sénégal. Tropical Medicine and International Health 3(8), 667-677.

Ryan, G. W. (1998) What do sequential behavioural patterns suggest about the medical decision-making process? Modelling home case management of acute illness in a rural Cameroonian village. Social Science and Medicine 46(2), 209-225.

Snow, R. W., Craig, M., Deichmann, U. \& Marsh, K. (2000) Evaluation de la mortalité, de la morbidité et des incapacités dues au paludisme dans les populations africaines, femmes enceintes exceptées. Bulletin of the World Health Organization, collection of papers No. 2, pp. $64-80$.

Tanner, M. \& Vlassof, C. (1998) Treatment-seeking behaviour for malaria: A typology based on endemicity and gender. Social Science and Medicine 46(4-5), 523-532.

Troy, A. (1999) Histoires de Pagnes: Dons Rituels, Circulation et Transmission dans une Société Bilinéaire (Sereer Sine du Hireena et de la Petite-Côte, Sénégal). Mémoire de DEA, Collège de France.

Vlassoff, C. \& Manderson, L. (1998) Incorporating gender in the anthropology of infectious diseases. Tropical Medicine and International Health 3(12), 1011-1019.

Willams, H. A. \& Jones, C. O. H. (2004) A critical review of behavioural issues related to malaria control in Sub-Saharan Africa: What contribution have social scientist made? Social Science and Medicine 59(3), 501-523.

World Health Organization (2000) WHO Expert Committee on Malaria. Twentieth report, WHO, Geneva, p. 892. 